DOI 10.37882/2223-2982.2021.11-2.09

\title{
КОМПОНЕНТЫ ГОТОВНОСТИ СТУДЕНТОВ КОЛЛЕДЖА К УЧАСТИЮ В КОНКУРСАХ ПРОФЕССИОНАЛЬНОГО МАСТЕРСТВА
}

\section{COMPONENTS OF COLLEGE STUDENTS READINESS TO PARTICIPATE IN PROFESSIONAL SKILL COMPETITIONS}

M. Druzhinina

M. Kurnosova

Summary: The article analyzes the components of college students' readiness to participate in professional skill competitions in pedagogical specialties. The components of readiness components in pedagogical and psychological research are presented. The main approaches to understanding readiness are highlighted: functional and personal. The definition of the concept of readiness of college students to participate in professional skill competitions is proposed and its components are defined: emotional-volitional, motivational, behavioral, personal and cognitive components.

Keywords: secondary vocational education, readiness, components of readiness, readiness to participate in competitions, WorldSkills, functional approach, personal approach, emotional-volitional, motivational, behavioral, personal and cognitive components.
Перед современным средним профессиональным образованием поставлена задача в выпуске мобильных, активных, креативных, имеющих профессиональные и личностные навыки и опыт работы студентах - будущих специалистах. Одним из способов повышения уровня профессиональных качеств и компетенций студентов являются конкурсы профессионального мастерства, которые способствуют эффективному развитию и совершенствованию компетенций у студентов, готовых к будущей профессиональной деятельности, к внедрению новых методик в практику работы.

Однако, на практике мы сталкиваемся с тем, что конкурсы профессионального мастерства (в частности WorldSkills) требуют от участников не только высокого уровня профессионального мастерства и профессиональной компетентности, но и ставят конкретные задачи перед личностью участника. В условиях конкурсной борьбы встает вопрос не только о профессиональной подготовке участников к конкурсу, но и о формировании готовности к участию в конкурсах профессионального мастерства. В настоящее время не вызывает сомнений тот факт, что в условиях конкурентной борьбы личностные качества конкурсантов напрямую влияют на уро-
Дружинина Мария Вячеславовна

d.n.н., профессор, ФГАОУ ВО «Северный (Арктический) федеральный университет имени М.В. Ломоносова»

m.druzhinina@narfu.ru

Курносова Марианна Александровна

Аспирант, ФГАОУ ВО «Северный (Арктический) федеральный университет имени М.В. Ломоносова»

kurnosovama@gmail.com

Аннотация: В статье проведен анализ компонентов готовности студентов колледжа к участию в конкурсах профессионального мастерства по педагогическим специальностям. Представлены составляющие компонентов готовности в педагогических и психологических исследованиях. Выделены основные подходы к пониманию готовности: функциональный и личностный. Предложено определение понятия готовности студентов колледжа кучастию в конкурсах профессионального мастерства и определены ее компоненты: эмоционально-волевой, мотивационный, поведенческий, личностный и когнитивный компоненты.

Ключевые слова: среднее профессиональное образование, готовность, компоненты готовности, готовность к участию в конкурсах, WorldSkills, функциональный подход, личностный подход, эмоционально-волевой, мотивационный, поведенческий, личностный и когнитивный компоненты.

вень их профессионального мастерства и, соответственно, результаты зачетных баллов. Практика успешной организации и проведения регионального чемпионата «Молодые профессионалы» (WorldSkills Russia) в Архангельской области по компетенциям R21 «Преподавание в младших классах» и R4 «Дошкольное воспитание», и собственный 4-летний опыт психолого-педагогической подготовки участников, показывает, что недостаток стрессоустойчивости, мотивированности, уверенности в себе снижает эффективность участия в конкурсных соревнованиях профессиональной направленности.

Однако, в психологической и педагогической науках явление готовности к участию в конкурсах профессионального мастерства не изучено, не описано и не проанализировано в достаточной степени. Отсутствует дефиниция готовности к участию в конкурсах профессионального мастерства, понимание сущности данного явления, его смыслового содержания, нет представления о структуре и составляющих данного явления.

В связи с этим изучение и разработка структуры и компонентов готовности студентов колледжа к участию в конкурсах профессионального мастерства представ- 
ляется актуальной для отечественной образовательной системы.

Основательные исследования феномена психологической готовности проводились в космической (Е.А. Лебедев), авиационной (В.Л. Марищук, Б.Л. Покровский), инженерной психологии (М.И. Дьяченко, В.А. Пономаренко).

Готовность была объектом многолетних исследований во всем мире с различных точек зрения: готовность ребенка к обучению в школе (Д.Б. Эльконин, Л.И.Божович, Е.Е.Кравцова, Л.А.Венгер), психологическая готовность к спортивным соревнованиям (А.М. Ахатова, И.В. Работина, А.Ц. Пуни), готовность к военным действиям (Б.И. Майор, В.Т. Доценко, А.Г. Караяни), готовность к профессиональной деятельности (М.И. Дьяченко, Л.А. Кандыбович, Л.А. Попов и др.).

Обратившись же к более узким исследованиям готовности к какой-либо деятельности мы обнаружили, что изучалась готовность студентов к воспитательной работе (Е.А. Леванов), В.П. Наумов исследует готовность будущих учителей к общению с подростками и т.д.

Проведя анализ психолого-педагогической литературы, мы установили, что на текущий момент выделяются два основных подхода к понятию готовности к какойлибо деятельности: функциональный и личностный.

Функциональное направление рассматривает готовность как особое психическое состояние, которое является своеобразной связкой между психическими процессами и личностью, приводит в действие психические процессы. Оно представлено исследованиями
Е.С. Кузьмина,Н.Д.Левитова, В.Н.Мясищева,Л.С.Несисяна, В.Н. Пушкина, Д.Н. Узнадзе, В.А. Ядова. В данном контексте готовность включает в себя не только различного рода осознанные и неосознанные установки на определенный действия, но и осознание задач, модели вероятного поведения, определение оптимальных способов действия, оценку своих возможностей в их соотношении с предстоящими трудностями и необходимостью достижения определенного результата.

Сторонники личностного подхода (М.И. Дьяченко, И.А. Зимняя, Л.А. Кандыбович, В.А. Крутецкий, В.А. Сластенин) подразумевают под готовностью устойчивую характеристику личности. Будучи заблаговременно сформированной, эта готовность становится значимой предпосылкой к успешной деятельности. Исследователи личностного подхода готовности определяют готовность как синтез свойств личности (интегральным свойством личности), который определяет ее пригодность к деятельности и включает в себя активное, положительное отношение к деятельности, некоторый опыт (знания, умения, навыки), умение организовать свой труд, работать самостоятельно, а также видеть перспективы развития.

Рассмотрев общее понимание готовности как таковой и готовности к какой-либо деятельности в частности, мы предприняли попытку сформулировать свое понимание готовности студентов колледжа к участию в конкурсах профессионального мастерства. В нашем понимании готовность студентов колледжа к участию в конкурсах профессионального мастерства - это целостное проявление личности, которое будучи заблаговременно сформированным, является важным условием успешной соревновательной деятельности в конкурсах

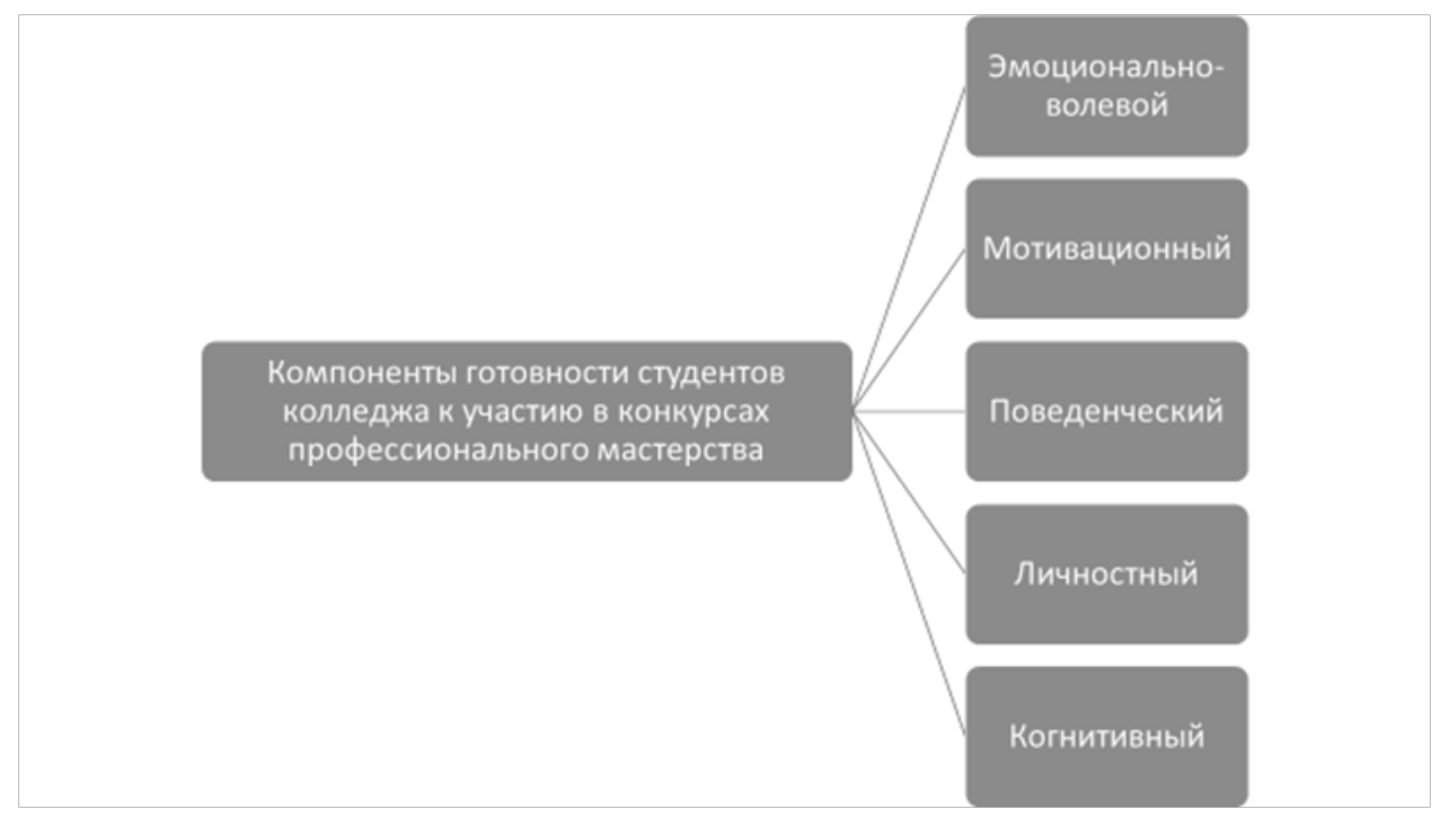

Рис. 1. Компоненты готовности студентов колледжа к участию в конкурсах профессионального мастерства. 
профессионального мастерства. Она должна включать в себя следующие компоненты: эмоционально-волевой, мотивационный, поведенческий, личностный и когнитивный компоненты (см.рис.1).

Так, например, эмоционально-волевой компонент готовности студентов колледжа к участию в конкурсах профессионального мастерства будет включать в себя в первую очередь положительное отношение к участию в конкурсах профессионального мастерства, необходимый и достаточный уровень эмоционального возбуждения (предвкушение соревнования), способность к самостоятельной регуляции своих эмоциональных состояний (которые могут быть вызваны негативными эмоциями в процессе конкурсного соревнования), уверенность студента в своих силах и индивидуально-личностные особенности, такие как: стрессоустойчивость, навыки саморегуляции, благоприятные эмоции, вызванные самим процессом прохождения конкурсных заданий соревнования.

Для мотивационного компонента должно быть характерно наличие устойчивых позитивных мотивов участия в конкурсе (мотив достижения, потребность успешно выполнять поставленные задачи, нацеленность на положительный результат, личностный смысл участия в конкурсе) и желание преодолевать возникающие в процессе выполнений конкурсных заданий соревнования препятствия.

Поведенческий компонент мы охарактеризуем моделями вероятного поведения (четким пониманием того, что необходимо делать, как себя вести на конкурсном мероприятии и как к нему готовиться), а также демон- страцией уверенного поведения в процессе выполнения конкурсных заданий.

Содержание личностного компонента мы определяем таким образом: оптимальное соответствие структуры характера, физиологических особенностей нервной системы, способностей и темперамента студента требованиям конкурсной деятельности; устойчивые профессионально важные особенности сенсорной и умственной сферы; склонность к педагогической и соревновательной деятельности и желание ей заниматься; навыки эффективной коммуникации с участниками соревновательного процесса.

И когнитивный компонент мы наполним следующим содержанием: усвоенные профессиональные знания, умения и навыки в соответствующей области конкурсного направления; готовность актуализировать знания, умения и навыки в необходимый момент.

Также, следует отметить, что готовность студентов колледжа к участию в конкурсах профессионального мастерства - система динамическая, все ее компоненты связаны между собой, но связи между ними подвижны и изменчивы, и в силу влияния объективных или субъективных условий деятельности каждый из них может временно стать ведущим.

Таким образом, мы предлагаем рассматривать готовность студентов колледжа к участию в конкурсах профессионального мастерства как многокомпонентную систему, как комплекс свойств и качеств личности, как целостное проявление личности, начало формирования которого лежит в подструктуре опыта и обусловлено в первую очередь знаниями, умениями и навыками.

\section{ЛИТЕРАТУРА}

1. Программа модернизации образовательных организаций, реализующих программы среднего профессионального образования, в целях устранения дефицита квалифицированных рабочих кадров в субъектах Российской Федерации, одобренная координационным советом по среднему профессиональному образованию Министерства образования науки Российской Федерации (одобрена Координационным советом по среднему профессиональному образованию Министерства образования науки Российской Федерации 25 апреля 2018 г.) - [Электронный ресурс] - Режим доступа: http://rcdpo. ru/download/programma-modernizacii-obrazovatelnyx-organizacij-realizuyushhix-programmy-srednego-professionalnogo-obrazovaniya-v-celyax-ustraneniyadeficita-kvalificirovannyx-rabochix-kadrov-v-subektax-rossijsko/.

2. Витвицкая С.С. Структура и критерии готовности магистров образования к педагогической деятельности // Вектор науки Тольяттинского Государственного Университета: Серия: Педагогика, психология. - № 2 (13). - 2013. - С. 59-63.

3. Дьяченко М. И., Кандыбович Л. А. Психологическая готовность человека к деятельности. — Минск, 1976. — 212 с.

4. Зеер Э., Сыманюк Э. Компетентностный подход к модернизации профессионального образования // Высшее образование в России. - 2005. - № 4. C. 23-30.

5. Ипполинова Н.В., Колесников М.А., Соколова Е.А. Система профессиональной подготовки студентов педагогического вуза: личностный аспект: монография. 2-е изд., доп. и перераб. СПБ.: Изд-во СПбГУ, 2010.

6. Корнеев Ю.В., Малыгин А.Г. Формирование ключевых компетенций в системе многоуровневого непрерывного профессионального образования // Модернизация общего и профессионального образования: сб. тр. всерос. науч.-практ. конф. Томск: ЗТТ, 2008.

7. Лебедев 0.Е. Компетентностный подход в образовании // Школьные технологии.-2004.-№5.-С.3-12. - [Электронный ресурс] - Режим доступа: http://pedlib.ru/Books/3/0389/3_0389-1.shtml 
8. Лежнина Л.В., Данилова О.В. Эмпирическое исследование компонентов психологической готовности к педагогической деятельности у студентов выпускных курсов // Казанский педагогический журнал. - 2019. - №2. - С.134-138.

9. Попов Л.М., Пучкова И.М. Теоретико-экспериментальное обоснование модели психологической готовности студентов к профессиональной деятельности // Образование и саморазвитие. - 2015. - № 1 (43). - С. 53-58.

10. Санжаева Р.Д. Психологическая готовность личности к деятельности как метакатегория // Образование. Личность. 0бщество. — 2012, №1. — C. $127-140$.

11. Сизикова Н.В. Смысловой компонент психологической готовности к спортивной деятельности: дис. ... канд. психол. наук. — Кемерово, 2008. — 182 с. 1

12. Старовойтова Л.И., Аришина Э.С. Преподаватель университета как субъект формирования студентов к профессиональной готовности // Проблемы современного педагогического образования: сборник научных трудов, 61(4). - Ялта, 2018. - С.11-14

13. Чимбеева С.В., Санжаева Р.Д. Структурно-содержательные характеристики компонентов психологической готовности юношества к семейным отношениям // Психологическая адаптация и психологическое здоровье человека в осложненных условиях жизненной среды: материалы II Всероссийской науч.-практ. конф. - М.: ЛЕНАНД, 2013. - С.459-467.

14. Чучалова 0.В. Мотивационная готовность к самореализации интеллектуальных способностей: автореф. дис. ... канд. психол. наук. — Томск, 2015. — 23 c.

○ Дружинина Мария Вячеславовна (m.druzhinina@narfu.ru), Курносова Марианна Александровна (kurnosovama@gmail.com).

Журнал «Современная наука: актуальные проблемы теории и практики»

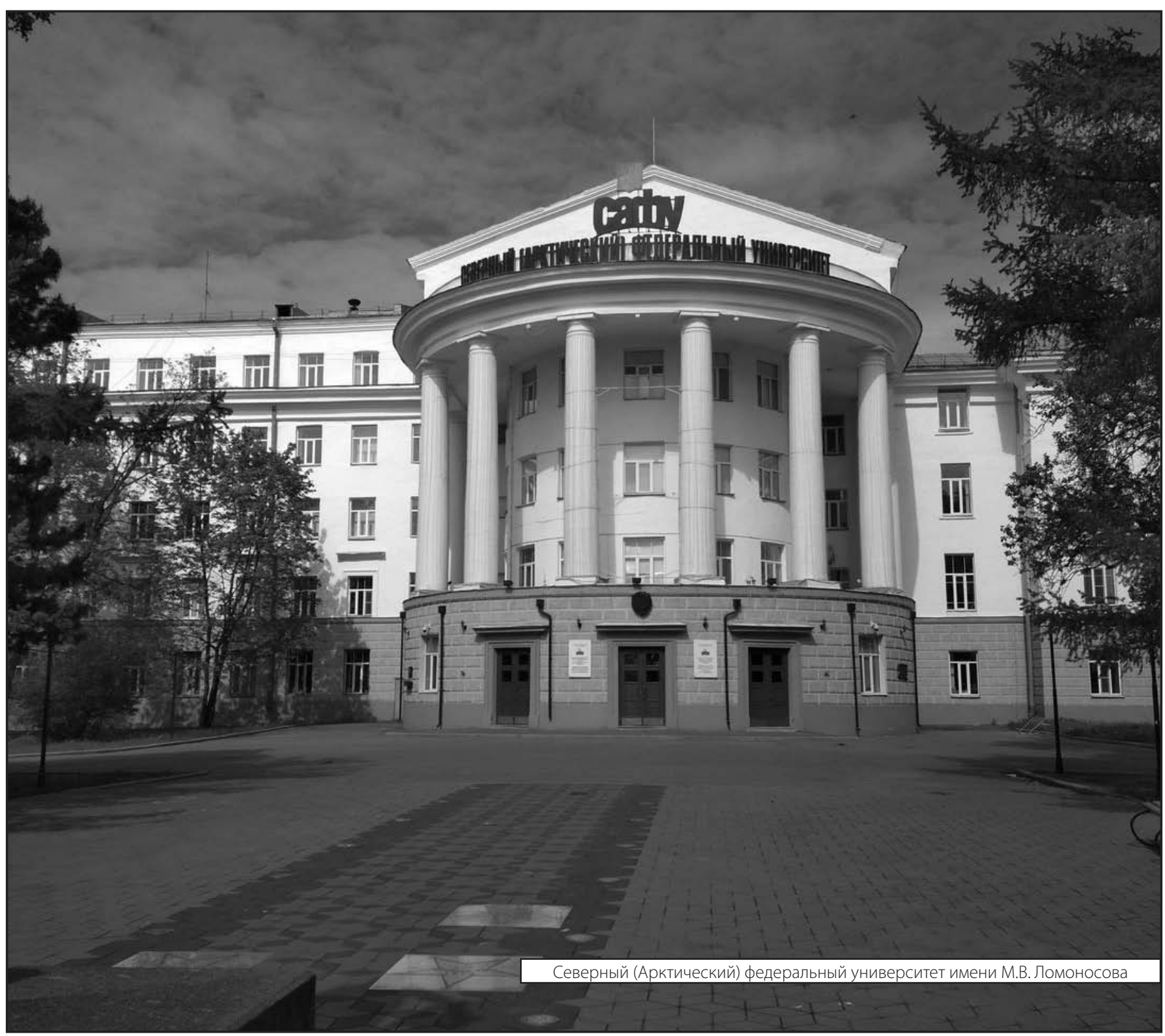

